\title{
Interprofessional education in mental health services: learning together for better team working
}

\author{
Daniel Kinnair, Elizabeth Anderson, Henderikus van Diepen \& Cath Poyser
}

\begin{abstract}
SUMMARY
Interprofessional education, learning which brings together different professional groups, helps to prepare practitioners for effective team-based collaborative practice and is now included in all undergraduate training programmes in the health professions. We explore the merits of team-based interprofessional learning, drawing on learning theory and mental health policy. We endorse the use of a practice-based interprofessional education model involving patients in which students experience the complexity of team working and the clinical team gain a more detailed analysis of team processes, which can enhance the quality of patient care. The model has been replicated for undergraduate education in mental healthcare and could easily be used for postgraduate staff. Interprofessional education at postgraduate level could foster the ongoing team-based reflective learning needed to enable mental health services in the UK to adapt to the dramatic changes both in their organisation and in the roles and responsibilities of individual professions.
\end{abstract}

\section{DECLARATION OF INTEREST}

D. K. is an elected board member of the Centre for the Advancement of Interprofessional Education (CAIPE). E. A. is a past CAIPE board member.

Interprofessional education (IPE) was originally defined by the Centre for the Advancement of Interprofessional Education (1997) and clearly articulated in 2002 (Barr 2002). There has been international agreement that it 'occurs when two or more professions learn about, from and with each other to enable effective collaboration and improve health outcomes' (World Health Organization 2010: p. 13). This definition implies that students from different professions must come together in the learning process to achieve their intended learning outcomes. In this way, students bring their uniprofessional specific knowledge and skills into interprofessional learning to mirror the complexity of team-based clinical practice.
Interprofessional education has existed in the formal preregistration curriculum for about 10 years, and was affirmed as essential by the General Medical Council in Tomorrow's Doctors (General Medical Council 2009). This directive is similarly reflected in curricula for nursing and all allied health professions (Nursing and Midwifery Council 2008; Health \& Care Professions Council 2012). As a result, students are emerging from preregistration courses primed to learn in this way (Barr 2007). Indeed, the Foundation Programme Curriculum expects ongoing training to include preparation for team working (section 1.4, Foundation Curriculum; UK Foundation Programme 2012) and competencies to interface with different specialties and professionals (section 7.9). It is implicit in the psychiatry core training curriculum (Royal College of Psychiatrists 2010) that good interprofessional collaboration is key for those who choose to train in psychiatry. In addition, all doctors in the UK are now required to produce evidence for revalidation, for which one of the domains is communication, partnership and team work (General Medical Council 2012).

This article will explore the paucity of interprofessional education in current postgraduate programmes for doctors and other practitioners preparing to work in mental health teams. We will offer solutions based on our extensive experience which are framed in sound theoretical principles for team-based learning and involve patients as a central component.

\section{Team working in mental health services}

Team working and collaborative practice have always been a key component of patient care in mental health services. This is because patients present with complex mental health needs and interrelated social problems that often require a response from medicine, nursing, psychology, occupational therapy and social work. Traditionally, the doctor has taken a leadership role relating to diagnosis, whereas treatment plans
Daniel Kinnair is a consultant in general adult psychiatry at Leicester General Hospital and an honorary senior lecturer in the Department of Medical and Social Care Education at the University of Leicester. Elizabeth Anderson is Professor of Interprofessional Education in the Department of Medical and Social Care Education at the University of Leicester. Henderikus van Diepen is a consultant in old age psychiatry and an honorary senior lecturer in the Department of Medical and Social Care Education, University of Leicester. Cath Poyser is an occupational therapist and clinical educator with Leicestershire Partnership NHS Trust. Correspondence Dr Daniel Kinnair, Maidstone Centre, St Peter's Health Centre, Sparkenhoe Street, Leicester LE2 OTA, UK. Email: Daniel. kinnair@leicspart.nhs.uk 
and long-term care - areas in which concepts such as recovery, support and therapy are important - have been shared across medicine, nursing, occupational health and psychology. In addition, the social worker places the patient (client) in their social and cultural context. On the whole, these teams have learnt 'on the job' how to work with each other. Community mental health teams (CMHTs) are seen as providing joined-up multiprofessional services for individuals with complex care needs (Glasby 2004a), and in the UK, the care programme approach (CPA) was designed to support team working (Department of Health 1990) and collaborative practice (Box 1). However, despite efforts within organisations to improve team working there continue to be errors, concerns and national inquiries that highlight poor team working within mental health services (Ritchie 1994; Prins 2004).

The day-to-day practicalities of team working in mental health services remain difficult, and conflicts and challenges arise when professions have different value bases and report to different statutory accountable structures. The concept of values within health and social care includes anything that is 'valued', and might embrace ethics, justice, principles, morals and individuals' personal beliefs. A particular problem, for example, is the sharing of information (Richardson 2006). A number of obstacles to good collaborative practice have been identified. These include structural, procedural, financial, professional and statusbased factors, not least of which is who takes the lead and has the power (Peck 2008).

A review of partnership working across different teams and organisations in mental healthcare delivery (Glasby 2004b) identified several barriers to good team working and possible solutions. The barriers included:

- professional self-interest, including aspects of autonomy and accountability

B0X 1 The care programme approach (CPA)

The key components of the CPA are:

- an interagency assessment of the individual's health and social care needs

- an assessment of risk factors for the individual or others

- a CPA care plan to address the assessed needs

- the identification of a care coordinator

- regular reviews

- the identification of gaps in service

(Department of Health 1990)
B0X 2 Effective partnerships

Effective partnerships can help agencies to:

- deliver coordinated packages of services to individuals

- tackle so-called 'wicked issues' (complex problems that cross traditional agency boundaries)

- reduce the impact of organisational fragmentation and minimise the effect of any perverse incentives that result from it

- align services provided by all partners with the needs of patients

- make better use of resources

- stimulate more creative approaches to problems

(Audit Commission 1998)

- financial resources and constraints

- procedural differences between teams.

No easy solutions to these difficulties were found.

There has been an ongoing call for more training to prepare practitioners to work effectively in teams (Whittington 2003; Hope 2004). Box 2 summarises the Audit Commission's (1998) explanation of how effective partnerships might help organisations. Box 3 lists the 'essential shared capabilities' in which all National Health Service (NHS) mental healthcare staff should be trained (Hope 2004).

\section{Team roles of psychiatrists}

There has been a plethora of documents looking at how psychiatrists should work in teams (Department of Health 2005). Psychiatrists' roles are changing to provide expertise in assessment and treatment and operate on a consultative model. Other team members (e.g. nurse prescribers) are taking on some of the roles more commonly

B0X 3 The 10 essential shared capabilities for all NHS staff

1 Working in partnership - with patients, carers, families, colleagues, etc.

2 Respecting diversity

3 Practising ethically

4 Challenging inequality

5 Promoting recovery

6 Identifying people's needs and strengths

7 Providing patient-centred care

8 Making a difference

9 Promoting safety and positive risk-taking

10 Personal development and learning

(Hope 2004) 
associated with doctors, and doctors within the team are asked to see only the patients with the complex problems. Responsibility for care, which once sat firmly with the psychiatrist, is now shared between team members. Care depends on collaborative work, with each team member sharing their unique skills and abilities.

\section{Current provision}

Interprofessional education has been endorsed for preregistration courses as it prepares undergraduate students for collaborative working (Barr 2012). There are examples of programmes for mental healthcare, although contact is often limited and not all professions are included (Carpenter 1995; Curran 2008). Looking at the educational continuum, there are also some examples of interprofessional education for postgraduate mental health teams, but these initiatives are rare, mostly because of the complexity of aligning postgraduate courses (Barnes 2000; Reeves 2006). There is evidence that attendance at postgraduate courses organised as part of CPD is higher among nursing staff than among psychiatrists and psychologists (McCann 2012). There is huge scope for developing more relevant interprofessional education relating to the complexity of mental healthcare for all professionals. In medicine, the need to provide evidence for revalidation might encourage the provision of postgraduate interprofessional education.

\section{Solutions: the way forward}

Interprofessional education may offer solutions for shaping professional behaviour and for developing effective teams. It focuses on theories of learning centred not on the individual but on learning with others in sociocultural clinical contexts. Its premise lies in adult learning theory, where the process of learning, i.e. through experience or reflection, is key (Knowles 1978; Kolb 1984; Wenger 1998). Interprofessional education at its best can set up a complex and challenging social learning environment that mirrors the realities of clinical practice and teaches effective team working (Bleakley 2006). There are obviously socially constructed and mediated power differentials in these mixed student interactions and managing these must be considered (Hean 2013).

\section{Undergraduate models of interprofessional education}

In its original version, the Leicester Model of Interprofessional Education was designed and developed with undergraduate students to enable them to appreciate the complexities of health

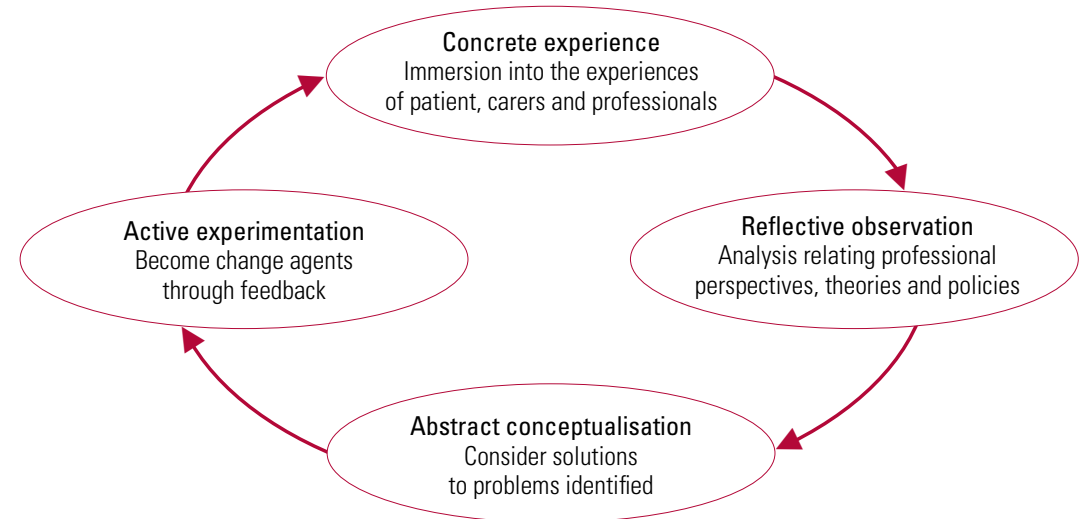

FIG 1

The learning cycle of the Leicester Model of Interprofessional Education (adapted from Kolb 1984).

and social care delivery in meeting the needs of disadvantaged inner-city communities (Lennox 1998, 2007). The model combines practical understanding of team working and collaborative practice using a patient-centred approach (Anderson 2009). It uses a learning cycle based on the work of Kolb (Fig. 1).

From the student's perspective learning takes place (cyclically) following four consecutive steps.

\section{Concrete experience}

Experiential learning in which students work with and learn from patients, carers and professionals in day-to-day clinical practice. The students are immersed in the complexity of team working, and patient/carer perceptions of care are central to and drive the learning.

\section{Reflective observation}

Students are helped in tutorials to apply theory and policy to their experiences and thus to gain a richer and deeper understanding of patients' and professionals' perspectives of care delivery. In this way, students come to understand professional roles and responsibilities.

\section{Abstract conceptualisation}

Students faced with the complexity of care are helped to reanalyse clinical problems and consider new ways to address and manage care. These new solutions are student generated and can often raise issues not yet considered by the professionals, mostly because students have more time to reflect on what they see.

\section{Active experimentation}

In the final stage, students feed back to the professional teams changes to practice that they think might improve patient outcomes and that might be introduced into day-to-day procedures. 


\section{Shadowing the professionals}

The Leicester model places patients at the heart of the experience for undergraduate interprofessional groups, and this mirrors team working with patients in practice (Department of Health 2008). The model has been evaluated from the perspective of students, professionals and patients (Anderson 2009). The learning template has been adopted in different team-based clinical settings, including mental healthcare (Kinnair 2012). The essence of the model is that students are given clinical responsibilities, becoming shadow teams accountable to the professional team. They analyse and explore the existing professional care plans for patients, and throughout are directly involved in the realities of day-to-day practice. In the mental health adaptation, the students mirror the work of a CMHT and feed back on interagency care plans. In this and other adaptations, student teams have identified unmet needs and unsafe practice (Anderson 2010; Lennox 2012).

\section{Involving patients in interprofessional education}

The involvement of patients has the benefit of putting the teaching in a real-life clinical context. The Department of Health and the Health and Care Professions Council (until 2012, the General Social Care Council) require the involvement of members of the public in education (Department of Health 2003; General Social Care Council 2003), and, as already mentioned, the Leicester Model of Interprofessional Education places patients at the centre of the cycle of experiential learning. Towle et al (2009) propose six levels of patient involvement, from case studies through to policy development. The level of engagement may be crucial to the patients' experience or perspective of the value they place on participating in interprofessional education.

A number of studies have shown the successful inclusion of patients in undergraduate interprofessional education (Cooper 2006; Anderson 2011). Patients involved in the mental health interprofessional education course in Leicester reported that they could see the purpose and benefit of bringing students from different professional groups together to learn (Kinnair 2012). They recognised that they received care provided by teams and that joined-up care between teams is sometimes difficult. Although patients were initially nervous about participating in the course, the overwhelming feedback was that they enjoyed taking part and felt that their contribution to education was valued. There is also evidence that postgraduate interprofessional education courses can have a positive effect on patient care (Zwarenstein 2005).

\section{Interprofessional education in postgraduate mental healthcare}

Effective interprofessional collaboration has been seen by policy makers as a key mechanism for tackling poor-quality service delivery, improving patient safety and minimising waste of resources, including clinical time (Department of Health 2001). However, despite repeated suggestions in national policy documents and statements that an interprofessional education approach be taken in mental healthcare, there is little evidence to demonstrate benefits in postgraduate training, and no national strategy.

There is published evidence to demonstrate the benefits of interprofessional education at the postgraduate level in a pilot project involving CMHTs (Reeves 2006). Interprofessional education was offered to two CMHTs, with the aim of improving collaborative working by providing an opportunity for team members to reflect on collaborative practice and the contribution to care made by each profession within the teams. The teams met for three 2-h workshops. The study reported that the workshops did help to clarify roles and were seen by participants as a valuable space to reflect on different professional perspectives.

The idea of different professional perspectives is an important one in health and social care, and particularly in mental healthcare, where successful recovery requires a biopsychosocial approach. Patients with mental health problems may also experience health inequalities dependent on income, housing, environment, powerlessness to effect change and wider notions of unfairness (Duggan 2002). A collaborative approach between different professionals and agencies is needed to tackle these complicated difficulties.

\section{From silo to interprofessional education}

There is an opportunity to improve the quality of mandatory training programmes within NHS trusts. Many of these courses are multiprofessional, but not truly interprofessional. Courses in areas such as risk assessment, child protection, working with vulnerable adults and resuscitation skills require good collaborative care in clinical practice, and could benefit from an interprofessional education approach. Within postgraduate medical education, most core and higher trainees are taught in uniprofessional silos, separately from other branches of medicine for the majority of the time. There is an opportunity to develop interprofessional educational events to 
cross some of the existing barriers. All psychiatrists will work with a wide variety of professional groups, including general practitioners, physicians and others, and there should be formal learning events to support the development of high-quality multi-agency work.

\section{Taking forward interprofessional education at postgraduate level}

Planning and implementing interprofessional education necessitates the involvement of faculties from different health and social care schools, within or across universities. This first step of bringing staff together from different services and backgrounds is often difficult and requires a collegiate approach. If patients are to be involved, it will also be necessary to include clinical, practice-based staff to identify, recruit and support them.

If interprofessional education events are to be successful, they should have several important characteristics. They need the shared enthusiasm of the different disciplines involved in the project, not only in the developmental phase, but to sustain and embed it in several different curricula (Reeves 2008). Staff must model good interprofessional practice and communication in their collaboration and facilitation of learning events. And events must stay abreast of changes in policy at a national level and service changes at a local level that can affect staff and collaborative efforts.

\section{Setting up a postgraduate course}

Three key steps need to be considered in the development of a postgraduate interprofessional education course. First, train and bring together the course leaders/facilitators so that they can:

- learn more about each other and begin to work interprofessionally, each representing their different professional training

- understand each other's curricula and professional body requirements

- learn more about the methods of interprofessional education and how to manage group dynamics

- establish intended learning outcomes relevant for all the participating professions

- engage with frontline practitioners and individuals from the teams that will be attending the course

- plan, where possible, for the involvement of patients and work with them in the early planning stages

- decide how the learning will influence practice.

Second, design teaching to align with the intended learning outcomes and assessment process:

- decide how the learning will take place

- draw on theory to underpin the teaching

- agree an assessment strategy.

Third, evaluate the outcomes:

- use assessments to see whether the students have learnt from the event

- evaluate the impact of the learning event on all participants/stakeholders.

There are many questions to be addressed and these can be aligned to consideration of the 'presage', 'process' and 'product' of learning - the 3P model (Biggs 1993). Table 1 shows the 3P model as adapted for interprofessional education by Freeth $\&$ Reeves (2004).

\section{TABLE 1 Using the 3P model ${ }^{\mathrm{a}}$ to shape a learning event in interprofessional education}

\begin{tabular}{|c|c|c|}
\hline $\begin{array}{l}\text { Presage } \\
\text { Factors such as: the context of learning, teacher } \\
\text { characteristics, learner characteristics }\end{array}$ & $\begin{array}{l}\text { Process } \\
\text { Considers approaches to teaching and learning }\end{array}$ & $\begin{array}{l}\text { Product } \\
\text { The impact of the learning on all stakeholders }\end{array}$ \\
\hline \multirow{2}{*}{$\begin{array}{l}\text { Decide which professions will take part } \\
\text { Is this the first time these students have learnt } \\
\text { interprofessionally? Preparation for the learning } \\
\text { should reflect this }\end{array}$} & $\begin{array}{l}\text { Where will the learning take place: classroom or } \\
\text { workplace? }\end{array}$ & $\begin{array}{l}\text { Consider how the course will be assessed and } \\
\text { evaluated }\end{array}$ \\
\hline & $\begin{array}{l}\text { If the course relates to the working of a CMHT it } \\
\text { should take place at a CMHT base }\end{array}$ & \multirow{7}{*}{$\begin{array}{l}\text { Evaluation will offer insights into how to improve } \\
\text { the learning, whereas assessments help show } \\
\text { where learning has taken place }\end{array}$} \\
\hline Design teaching to take into account mental health & Environment is important to help the learning & \\
\hline $\begin{array}{l}\text { services legislation } \\
\text { Will the course meet the needs of the clinical } \\
\text { directors? }\end{array}$ & $\begin{array}{l}\text { Train facilitators to help them manage group } \\
\text { dynamics, as the various professional groups will } \\
\text { bring different values to their practice and different }\end{array}$ & \\
\hline \multirow{2}{*}{$\begin{array}{l}\text { Involve management: they will be more likely to } \\
\text { release staff if they can see that the learning might } \\
\text { improve the way staff work together }\end{array}$} & perceptions of power in clinical areas & \\
\hline & $\begin{array}{l}\text { Structure the learning to enable participants to feel } \\
\text { comfortable working and learning together }\end{array}$ & \\
\hline Design appropriate preparation materials & How will the course materials (e.g. workbooks, & \\
\hline $\begin{array}{l}\text { Consider the ethical issues if patients are involved } \\
\text { (e.g. consent) }\end{array}$ & e-tivities) help learning? & \\
\hline
\end{tabular}

a. The 3P model was proposed by Biggs (1993) and adapted for interprofessional learning by Freeth \& Reeves (2004).

CMHT, community mental health team. 


\section{Discussion}

There is still a need for interprofessional education to be firmly embedded for all trainee and consultant psychiatrists. We have offered one model, familiar to us at Leicester, which has been evaluated and adapted for use in mental health settings. Patient-centred models need to be further developed, especially where they offer the opportunity to improve practice. An alternative model that is popular in postgraduate education is the Quality Improvement Programme (Health Foundation 2012), although it is important to avoid delivering this in uniprofessional silos.

\section{Psychiatrists should take the lead}

Psychiatrists involved in postgraduate training must work collaboratively with educators in other health and social care professions to forward interprofessional education. This would address concerns that medical faculties have been slow to support interprofessional education, in part because of the recognised imbalance of status and power (Hean 2006; Curran 2007; Whitehead 2007).

Caution is needed not only to create a balance of those leading interprofessional education from across the professions, but also to ensure the right balance of students who attend. In their feedback on interprofessional education events, social work students continue to express concerns about the 'lack of respect' shown to them by medical students and the dominance of the medical model in assessing patient need (Smith 2008). However, although individual research papers have highlighted a perceived lack of medical participation in interprofessional education, the interprofessional education agenda both nationally and internationally has been supported by many prominent clinicians, including the late Dr John Horder, who founded the Centre for the Advancement of Interprofessional Education (CAIPE) and was a past President of the Royal College of General Practitioners.

\section{Trusting the evidence base}

There are several examples in the literature of the benefits of interprofessional education at both undergraduateandpostgraduatelevel. Theseinclude learning events on breaking bad news (Wakefield 2006), community healthcare (Anderson 2003) and team working and communication (Parsell 1998). The advantages of interprofessional education have included clarification of uniprofessional roles and responsibilities, and identifying where roles are similar and overlap. Interprofessional education allows students to experience clinically realistic team working situations, and allows potential conflicts to be identified and discussed. Few health and social care practitioners practise in isolation, and interprofessional education is a vehicle that allows students to experience collaborative working at an undergraduate or postgraduate level. There is longitudinal evidence that interprofessional education programmes at the undergraduate level produce attitudinal and behavioural changes that remain after graduation (Pollard 2008). Students trained in programmes that included interprofessional education were more confident in their interprofessional relationships and communication skills. If mental health services are to become more efficient and effective, interprofessional working and communication will be key to individual professional groups working together.

Interprofessional education is becoming increasingly common in health and social care undergraduate curricula (Hammick 2007). The evidence for interprofessional education for undergraduates is also growing and it is important that we develop relevant and interesting educational tools to teach different groups of postgraduates the skills necessary for team work and collaboration.

\section{Summary}

There is a clear drive to implement and embed interprofessional education in undergraduate curricula to help reinforce students' preparation for interprofessional team working after graduation (Barr 2006). This focus has also shown that students can become agents of change, not only for individual patients but also, potentially, for future practice within the NHS and social care systems.

Postgraduate education is in danger of being left behind, but interprofessional education at this level may be an opportunity to train and develop staff to implement the huge changes occurring in most NHS-based mental health teams and services. It may also give staff groups the space to reflect on changes to services and their own and their colleagues' roles in these changes.

\section{References}

Anderson ES, Lennox A, Petersen S (2003) Learning from lives: a model for health and social care education in the community context. Medical Education, 37: 59-68.

Anderson ES, Lennox A (2009) The Leicester Model of Interprofessional Education: developing, delivering and learning from student voices for 10 years. Journal of Interprofessional Care, 23: 557-73.

Anderson ES, Thorpe LN (2010) Learning together in practice: an interprofessional education programme to appreciate teamwork. Clinical Teacher, 7: 19-25. 
Anderson ES, Ford J, Thorpe LN (2011) Learning to listen: improving students' communication with disabled people. Medical Teacher, 32: 1-9.

Audit Commission (1998) A Fruitful Partnership: Effective Partnership Working. Audit Commission.

Barnes D, Carpenter J, Bailey D (2000) Partnerships with service users in interprofessional education for community mental health: a case study. Journal of Interprofessional Care, 14: 189-200.

Barr H (2002) Interprofessional Education Today, Yesterday and Tomorrow (Occasional Paper 1). Higher Education Academy, King's College London.

Barr H, Freeth D, Hammick M, et al (2006) The evidence base and recommendations for interprofessional education in health and social care. Journal of Interprofessional Care, 20: 75-8.

Barr H (2007) Piloting Interprofessional Education: Four English Case Studies (Occasional Paper 8). Higher Education Academy, King's College London.

Barr H, Low H (2012) Interprofessional Education in Pre-registration Courses: A CAIPE guide for Commissioners and Regulators of education. CAIPE.

Biggs J (1993) From theory to practice: a cognitive systems approach. Higher Education Research and Development, 12: 73-85.

Bleakley A (2006) Broadening conceptions of learning in medical education: the message from teamworking. Medical Education, 40 : 150-7.

Carpenter J (1995) Interprofessional education for medical and nursing students: evaluation of a programme. Medical Education, 29: 265-72.

Centre for the Advancement of Interprofessional Education (1997) Interprofessional education - a definition. CAIPE Bulletin, 13: 19.

Cooper H, Spencer-Dawe E (2006) Involving service users in interprofessional education: narrowing the gap between theory and practice. Journal of Interprofessional Care, 20: 603-17.

Curran VR, Sharpe D, Forristall J (2007) Attitudes of health sciences faculty members towards interprofessional teamwork and education. Medical Education, 41: 892-6

Curran VR, Sharpe D, Forristall J, et al (2008) Student satisfaction and perceptions of small group process in case-based interprofessional learning. Medical Teacher, 30: 431-3.

Department of Health (1990) The Care Programme Approach for People with a Mental IIIness, Referred to Specialist Psychiatric Services (HC(90)23/LASSL(90)). TSO (The Stationery Office).

Department of Health (2001) Working Together - Learning Together: A Framework for Lifelong Learning for the NHS. Department of Health.

Department of Health (2003) Changing Workforce Programme: Pilot site Report. TSO (The Stationery Office).

Department of Health (2005) New Ways of Working for Psychiatrists: Enhancing Effective Person Centred Services through New Ways of Working in Multidisciplinary and Multiagency Contexts. Final Report But Not the End of the Story. TSO (The Stationery Office).

Department of Health (2008) Refocusing the Care Programme Approach: Policy and Positive Practice Guidance. TSO (The Stationery Office)

Duggan M, Cooper A, Foster J (2002) Modernising the Social Model in Mental Health: A Discussion Paper. Social Perspectives Network.

Freeth D, Reeves $S$ (2004) Learning to work together: using the presage, process and product (3P) model to highlight decisions and possibilities. Journal of Interprofessional Care, 18: 43-56.

General Medical Council (2009) Tomorrow's Doctors: Outcomes and Standards for Undergraduate Medical Education. GMC.

General Medical Council (2012) Ready for Revalidation: The Good Medical Practice Framework for Appraisal and Revalidation. GMC

General Social Care Council (2003) Staff Guidance on Interim Payment Policy to Service Users: Report Summary. GSCC.

Glasby $\mathrm{J}$ (2004a) A healthy dose of partnership. Community Care, 1549: 56.
Glasby J, Lester H (2004b) Cases for change in mental health: partnership working in mental health services. Journal of Interprofessional Care, 18: 7-16.

Hammick M, Freeth D, Koppel I, et al (2007) A Best Evidence Systematic Review of Interprofessional Education (BEME Guide no 9). Best Evidence Medical Education.

Health \& Care Professions Council (2012) Standards of Education and Training. HCPC

Health Foundation (2012) Quality Improvement Training for Healthcare Professionals. Health Foundation.

Hean S, MacLeod Clark J, Adams K, et al (2006) Will opposites attract? Similarities and differences in students' perceptions of the stereotype profiles of other health and social care professional groups. Journal of Interprofessional Care, 20: 162-81.

Hean S, O'Halloran C, Craddock D, et al (2013) Testing theory in interprofessional education: social capital as a case study. Journal of Interprofessional Care, 27: 10-7.

Hope R (2004) The Ten Essential Shared Capabilities: A Framework for the Whole of the Mental Health Workforce. Department of Health.

Kinnair DJ, Anderson ES, Thorpe LN (2012) Development of interprofessional education in mental health practice: adapting the Leicester model. Journal of Interprofessional Care, 26: 189-97.

Knowles M (1978) The Adult Learner: A Neglected Species. Gulf Publishing.

Kolb DA (1984) Experiential Learning. Prentice-Hall.

Lennox A, Petersen S (1998) Development and evaluation of a community based, multiagency course for medical students: a descriptive study. BMJ, 316: 596-9

Lennox A, Anderson ES (2007) The Leicester Model of Interprofessional Education: A Practical Guide for Implementation in Health and Social Care (Higher Education Academy Medicine, Dentistry and Veterinary Medicine Special Report 9). MEDEV.

Lennox A, Anderson ES (2012) Delivering improvements in patient care: the application of the Leicester Model of Interprofessional Education. Quality in Primary Care, 20: 219-26.

McCann E, Higgins A, Maguire G, et al (2012) A survey of pedagogical approaches and quality mechanisms used in education programs for mental health professionals. Journal of Interprofessional Care, 26 : 383-9.

Nursing and Midwifery Council (2008) The Code: Standards of Conduct, Performance and Ethics for Nurses and Midwives. NMC London.

Parsell G, Spalding R, Bligh J (1998) Shared goals, shared learning: evaluation of a multiprofessional course for undergraduate students. Medical Education, 32: 304-11.

Peck E, Dickinson H (2008) Managing and Leading in Inter-Agency Settings. Policy Press.

Pollard K, Miers M (2008) From students to professionals: results of a longitudinal study of attitudes to pre-qualifying collaborative learning and working in health and social care in the United Kingdom. Journal of Interprofessional Care, 22: 399-416.

Prins H (2004) Mental health enquiries - 'Cui Bono'? In The Age of the Inquiry: Learning and Blaming in Health and Social Care (eds N Stanley, J Manthorpe): 19-38. Routledge.

Reeves S, Freeth D (2006) Re-examining the evaluation of interprofessional education for community mental health teams with a different lens: understanding presage, process and product factors. Journal of Psychiatric and Mental Health Nursing, 13: 765-70.

Reeves S (2008) Planning and implementing a collaborative clinical placement for medical, nursing and allied health students: a qualitative study. Medical Teacher, 30: 699-704.

Richardson S, Asthana S (2006) Interagency information sharing in health and social care services: the role of professional culture. British Journal of Social Work, 36: 657-69.

\section{MCO answers \\ 1 e 2 e $3 d \quad 4$ e 5 e}


Ritchie J, Dick D, Lingham R (1994) Report of the Inquiry into Care and Treatment of Christopher Clunis. North East Thames and South East Thames Regional Health.

Royal College of Psychiatrists (2010) A Competency Based Curriculum for Specialist Core Training in Psychiatry: Core Training in Psychiatry CT1-CT3. Royal College of Psychiatrists (http://www.rcpsych.ac.uk/pdf/ CORE_CURRICULUM_2010_Mar_2012_update.pdf).

Smith $\mathrm{R}$, Anderson L (2008) Interprofessional learning: aspiration or achievement? Social Work Education, 27: 759-76.

Towle A, Bainbridge L, Godolphin W, et al (2009) Active patient involvement in the education of health professionals. Medical Education, 44: 64-74.

UK Foundation Programme (2012) The UK Foundation Programme Curriculum. UK Foundation Programme.

Wakefield A, Cocksedge S, Boggis C (2006) Breaking bad news: qualitative evaluation of an interprofessional learning opportunity. Medical Teacher, 28: 53-8.
Wenger E (1998) Communities of Practice: Learning, Meaning and Identity. Cambridge University Press.

Whitehead C (2007) The doctor dilemma in interprofessional education and care: how and why will physicians collaborate. Medical Education, 41: 1010-6.

Whittington C (2003) A model of collaboration. In Collaboration in Social Work Practice (eds J Weinstein, C Whittington, T Leiba): 39-62. Jessica Kingsley Publishers.

World Health Organization (2010) Framework for Action on Interprofessional Education and Collaborative Practice. WHO.

Zwarenstein M, Reeves S, Perrier L (2005) Effectiveness of prelicensure interprofessional education and post-licensure collaborative interventions. Journal of Interprofessional Care, 19 (suppl 1): 148-65.

\section{MCOs}

Select the single best option for each question stem

\section{Interprofessional education has been} defined as:

a bringing different professionals together to learn

b bringing two or more professionals together to learn about each other

c bringing teams together to develop a service

d bringing staff from health and social care together to learn about each other's roles

e bringing two or more professionals together to learn from and about each other to improve collaboration and quality of care.

\section{Patients should be involved:}

a at the planning and course development phase

$b$ in facilitating the course

c in the course to share their experiences and reflections of care

$d$ in both a and $c$ above

$\mathrm{e}$ in $\mathrm{a}, \mathrm{b}$ and $\mathrm{c}$ above.
3 Interprofessional education is best delivered:

a in clinical settings

$\mathrm{b}$ in classrooms

c at universities

$\mathrm{d}$ at a location to mirror the course aims and intended learning outcomes

e in whatever rooms are available within the hospital.

4 Barriers to developing interprofessional education can include:

a time commitments of staff

b bringing together teaching and clinical staff from different professional groups and organisations

c the funding needed for patient involvement and facilitators

d negative views of teaching staff and students

e all of the above.
5 Interprofessional education courses require:

a keen and motivated teaching staff from one profession

b keen and motivated staff from several professions

c staff who have had training in interprofessional education facilitation

$\mathrm{d}$ both a and $\mathrm{c}$

e both $b$ and $c$. 